\title{
TOXICITY ANALYSIS OF RGD-CHITOSAN FROM SHRIMP SHELL SCAFFOLD MEMBRANES TOWARD HUMAN DENTAL PULP CELLS
}

\section{MAULDINA SHABRINA, DEWI FATMA SUNIARTI*, LISA R AMIR, ERIK IDRUS}

\author{
Department of Oral Biology, Faculty of Dentistry, Universitas Indonesia, Jakarta, Indonesia. Email: dewisuniarti@yahoo.com
}

Received: 21 April 2017, Revised and Accepted: 18 August 2017

\section{ABSTRACT}

Objective: This study aimed to analyze RGD-Chitosan from Shrimp Shells' Scaffolds' (RCSSS) and CSSS membrane toxicity toward human dental pulp cells.

Methods: Human dental pulp cells were cultured for 5 days and then exposed to RCSSS or CSSS membranes for 24 hrs. Cell viability was determined using an MTT assay method.

Results: Cell viability of the RCSSS group and CSSS group was higher than the cell viability of the control group. The cell viability of the RCSSS group $2 \mathrm{mg}$ (537.39\%) was significantly higher than the CSSS group $2 \mathrm{mg}(301.74 \%)$.

Conclusions: RCSSS membranes were not toxic toward human dental pulp cells and showed better effect toward human dental pulp cells compared to CSSS membranes.

Keywords: Chitosan, Human dental pulp cells, RGD-chitosan, Toxicity.

(C) 2017 The Authors. Published by Innovare Academic Sciences Pvt Ltd. This is an open access article under the CC BY license (http://creativecommons. org/licenses/by/4. 0/) DOI: http://dx.doi.org/10.22159/ijap.2017.v9s1.07_08

\section{INTRODUCTION}

Bone destruction can be caused by trauma, systemic disease, congenital abnormalities, and pathological conditions, such as in periodontitis, tumors, and cysts [1]. Bone destruction generally can cause significant bone loss and requires surgical treatment [2]. Until now, the use of autograft as a bone graft is still the gold standard to repair and regenerate bone defects [3]. Autograft shows good biocompatibility, does not induce the immune reaction, and can support osteoinduction, osteoconduction, and osteogenesis when it is used as a bone graft. However, in its application, bone grafts also show several clinical issues, such as morbidity, pain, and hypersensitivity in the donor area, a limited number of fairly large bone defects, and the need for additional surgery to harvest autografts from the patient's tissue [3]. These clinical issues have increased the need of substitute biomaterial as an alternative to bone grafts, especially in a case of large bone defects. One substitute is chitosan biomaterial, which can be used as a scaffold for bone tissue engineering [4].

Nowadays, tissue engineering is being widely studied and developed in hopes of better being able to regenerate tissue. The general principle of tissue engineering is to combine cells or vital tissues with synthetic supports or biomaterials that can be later transplanted to form new tissue or organs that functionally, structurally, or mechanically are as good as or even better than the original tissue [5]. One of the important components in tissue engineering is a scaffold. A scaffold is a three-dimensional structure that acts as a support for cell adhesion and deposition of an extracellular matrix, as well as allowing the transportation of gas, nutrition, and growth factors for cell proliferation and differentiation. Ideally, the scaffold has to be biocompatible, meaning it does not induce an immune reaction, is non-toxic, possesses a biodegradability property, and contains adequate porosity to support cell penetration [6].

One of the materials that can be used as a scaffold is chitosan. Chitosan derived from a material known as chitin, which is taken from shrimps crabs, lobsters, and other invertebrates [7]. In the past 20 years, chitosan has been widely studied for its scaffold potential to be used in tissue engineering because it possesses good biocompatibility and biodegradability. In addition, chitosan also has physical properties that enable it to be formed into a scaffold with a variety of structures, such as membrane, sponge, and fiber, all with adequate porosity for bone tissue engineering $[8,9]$. Based on the previous studies, chitosan used as a scaffold showed the capability to improve the proliferation of dental pulp stem cells (DPSCs) in culture. DPSCs are stem cells found in dental pulp and have the capability to differentiate into odontoblasts, osteoblasts, adipocytes, chondrocytes, myoblasts, and neural cells in vitro. In addition, DPSCs are also considered the appropriate candidate for bone formation because of its cell subpopulation, which has the capability to differentiate into a variety of cell types, including preosteoblasts in culture. It is also capable of generating bone tissue when transplanted in vivo [10].

As an attempt to improve its role as a scaffold, chitosan can be combined with other biomaterials, such as Arg-Gly-Asp (RGD) [11]. RGD is a peptide linked to cell adhesion and also plays a role in tissue regeneration by guiding cell migration [12]. RGD is commonly found in various bone proteins, such as fibronectin, vitronectin, fibrinogen, osteopontin, and bone sialoprotein [13]. Based on the previous studies, adding or combining RDG into a chitosan scaffold was reported to improve the biocompatibility of that chitosan $[11,14]$. Currently, the Indonesia National Atomic Energy Agency (BATAN) has been developing chitosan scaffolds from shrimp shells in the form of a membrane combined with RGD. However, based on the ISO standard 10993, before the scaffold can be transplanted or used in tissue engineering, that scaffold should undergo a biocompatibility test [15]. The test should be performed to avoid any negative effect that may arise after the scaffold comes in contact with body tissue. One of the tests that can be performed based on the ISO standard 10993 is a toxicity test in vitro. This study aimed to analyze RGD-chitosan from shrimp shells' scaffolds' (RCSSS) and CSSS membrane toxicity toward human dental pulp cells. All the scaffolds were in the form of membranes which were manufactured by the Indonesia National Atomic Energy Agency (BATAN). In this study, the cells used were human dental pulp cells that were isolated from intact and healthy human dental pulp extracted after orthodontic treatment.

\section{METHODS}

This study is based on experimental laboratory research conducted at the Laboratory of Oral Biology, Faculty of Dentistry, Universitas 
Indonesia from July to August 2016. The test material in this study was RCSSS in the form of a membrane manufactured by BATAN with the following specifications: Degree of deacetylation 95\%, molecular weight $75.000 \mathrm{Da}$, membrane size $2.5 \mathrm{~cm} \times 1 \mathrm{~cm}$, and membrane weight $23.1 \mathrm{mg}$. Before use, each chitosan membrane was initially cut and weighed into $1 \mathrm{mg}$ and $2 \mathrm{mg}$ and then sterilized in a laminar flow (UV) for 10 minutes. The pilot study showed that $1 \mathrm{mg}$ and $2 \mathrm{mg}$ were the correct minimum concentrations for testing on a 96-well plate. The cell culture medium used in this study was the $\alpha$-minimum essential medium solution and FBS from Gibco (USA), as well as penicillin, streptomycin, and amphotericin B which were produced by Sigma (USA). The toxicity analysis in this study was performed with the MTT assay method using MTT powder produced by Biomatrix (Fig. 1).

\section{Isolation of human dental pulp}

The sample in this study was human dental pulp isolated from intact and healthy human dental pulp extracted from orthodontic treatment. Human dental pulp cells were isolated following the method performed by Gronthos in 2000. The tooth was first cleaned, and then, crushed using pestle and mortar. Pulp tissue was then taken using an extirpation needle; then, it was cut using sterile scissors. In this study, cell isolation was also performed using collagenase enzyme $(3 \mathrm{mg} / \mathrm{ml})$ and dispase enzyme $(4 \mathrm{mg} / \mathrm{ml})$ by adding the enzyme to a tube containing the pulp tissue, followed by incubation for $1 \mathrm{hr}$. The obtained human dental pulp cells were then cultured. The cells on the third-to-fifth passages were used for the experiments.

\section{Exposure to test material}

Each CSSS in the form of a membrane and RCSSS in the form of a membrane was cut and weighed to obtain a scaffold that weighed $1 \mathrm{mg}$ and $2 \mathrm{mg}$. The scaffold membrane was then inserted into a microcentrifuge tube of $1.5 \mathrm{ml}$ and sterilized inside a safety cabinet with UV exposure for 10 minutes. Human dental pulp cell $\left(2 \times 10^{4}\right)$ was cultured in a 96-well plate, with each sample in the control group, and the treatment group performed at least twice (two fold). The complete culture medium used in this study was a $\alpha$-MEM culture medium in $50 \mathrm{ml}$ medium that contained $10 \% \mathrm{FBS}, 100$ units $/ \mathrm{ml}$ penicillin, $100 \mu \mathrm{g} / \mathrm{ml}$ streptomycin, and $0.25 \mu \mathrm{g} / \mathrm{ml}$ amphotericin B. The control group was comprised of human dental pulp cultured in a complete culture medium without exposure to the test material. Meanwhile, the treatment group was comprised of cells exposed to CSSS in the form of a membrane and RCSSS in the form of a membrane $1 \mathrm{mg}$ and $2 \mathrm{mg}$. Before being exposed to the test material, those cells were initially cultured for 5 days to allow the cells to grow. On the $6^{\text {th }}$ day, the scaffold membrane previously weighed was then inserted into each well of the treatment group. After that, the cells in the 96-well plate were incubated in a $\mathrm{CO}_{2}$ incubator $\left(37^{\circ} \mathrm{C}, 5 \% \mathrm{CO}_{2}\right)$ for $24 \mathrm{hrs}$, and the cell viability was analyzed using an MTT assay.

\section{Viability test using MTT assay}

First, some of the existing culture medium was discharged in each well. $15 \mu \mathrm{l}$ of MTT solution was then added into each well before the well was incubated in a $\mathrm{CO}_{2}$ incubator $\left(37^{\circ} \mathrm{C}, 5 \% \mathrm{CO}_{2}\right)$ for $3 \mathrm{hrs}$. After $3 \mathrm{hrs}, 150 \mu \mathrm{l}$ of acidified isopropanol solution was added to each well, and then, the 96 well plates were put on a shaker for $1 \mathrm{hr}$ at room temperature to dissolve the Formazan crystals that have formed. The OD value was then read using an enzyme-linked immunosorbent assay (ELISA) reader at $490 \mathrm{~nm}$ wavelength, and the viability of human dental pulp cell (\%) was calculated.

Data interpretation was done by comparing the viability of the human dental pulp cells (\%) of the treatment group with the viability of the human dental pulp cells (\%) of the control group. The experiment was performed twice, and in each experiment, each group was made at least twice (two fold).

\section{Data analysis}

The significant difference from the viability of the human dental pulp cells (\%) of the control group and the treatment group was analyzed statistically using a one-way analysis of variance (ANOVA) test.

\section{RESULTS}

In this study, human dental pulp cells were cultured in a $\alpha$-MEM culture medium that contained penicillin, streptomycin, amphotericin $B$, and FBS. Before being exposed to the test materials, the cells were cultured in a $\mathrm{CO}_{2}$ incubator $\left(37^{\circ} \mathrm{C}, 5 \% \mathrm{CO}_{2}\right)$ for 5 days until the cells had grown sufficiently. Fig. 2 shows the human dental pulp cells on the $5^{\text {th }}$ day at $\times 10$ magnification.

Effect of exposure of RCSSS in the form of a membrane to the viability of human dental pulp cells

The effect of the exposure of RCSSS in the form of a membrane to the viability of the human dental pulp cells was analyzed using an MTT assay and OD value, or the absorbance was read using an ELISA reader with $490 \mathrm{~nm}$ wavelength. The OD value was then expressed in cell viability (\%) toward the control cell (Fig. 3).

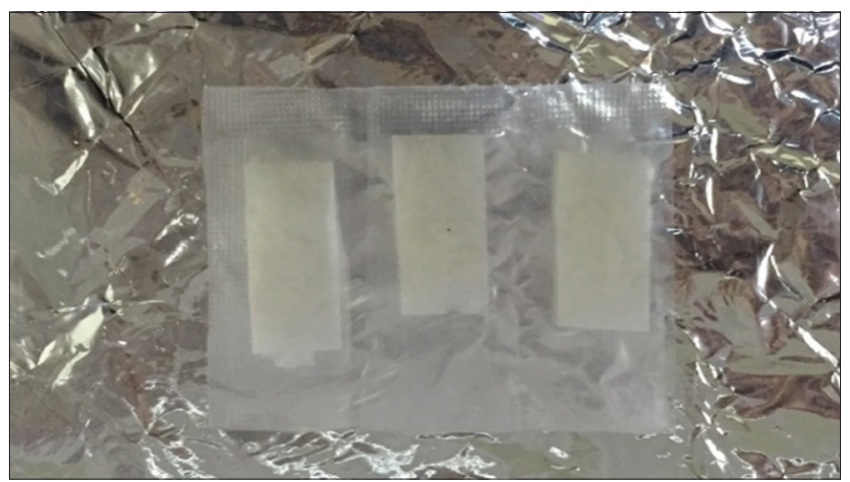

Fig. 1: Sample of RGD chitosan from shrimp shell scaffold in the form of a membrane

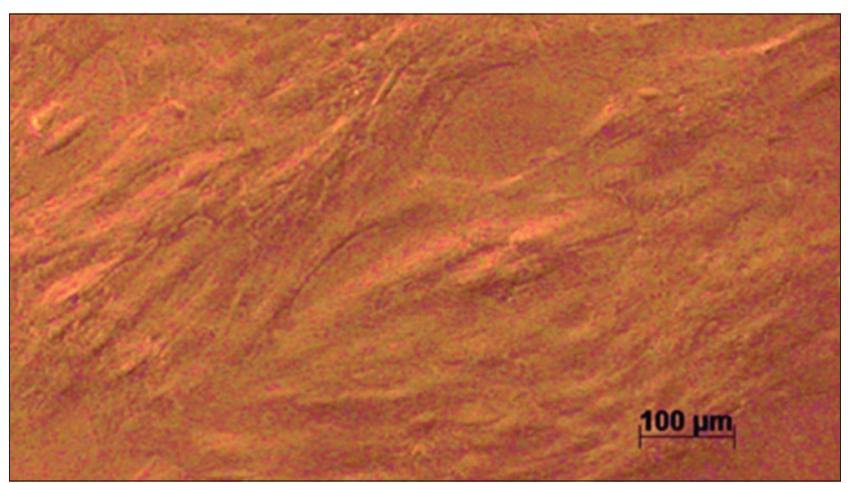

Fig. 2: Human dental pulp cells on the $5^{\text {th }}$ day

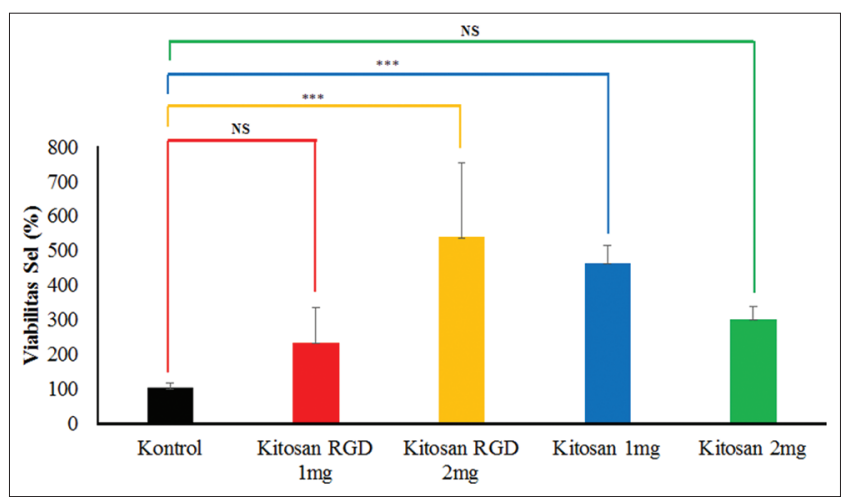

Fig. 3: Graphic of the effect of the exposure of RGD chitosan from shrimp shell scaffold in the form of a membrane to the viability of human dental pulp cells 
The graphic shows that the cell's viability in the treatment group was higher than the control group. The data normality test using Shapiro-Wilk test revealed that the data had a normal distribution $(p>0.05)$. Based on the homogeneity test performed, the data were not homogeneous or identical. However, because of the same amount of data in each group, the homogeneity test or test for equality of the variances could be ignored. After the normality and homogeneity test, an ANOVA test was then performed to compare the mean differences between the five groups. Based on that test, the significance level was $<0.05$, meaning each of the five groups was different from each other.

To determine whether there was a significant difference between the groups being compared, a statistical analysis using one-way ANOVA with post hoc test (Tukey-Bonferroni) was performed. A one-way ANOVA was selected in this study because there were five data groups regarding cell viability. The one-way ANOVA test with post hoc (Tukey-Bonferroni) showed that there was a significant difference between the viability of human dental pulp cells (\%) in the control group and the treatment group that has been exposed to $2 \mathrm{mg}$ RCSSS in the form of a membrane $(\mathrm{p}<0.001)$ and the other treatment group that has been exposed to $1 \mathrm{mg}$ CSSS in the form of a membrane $(\mathrm{p}<0.001)$. However, based on the test, even though it was revealed that the viability of human dental pulp cells exposed to $1 \mathrm{mg}$ RCSSS in the form of a membrane and $2 \mathrm{mg}$ CSSS in the form of a membrane was higher than the control group, it was not significantly different $(p>0.05)$.

\section{Comparison between the treatment groups}

In Fig. 4, the viability of human dental pulp cells (\%) in the treatment group exposed to $2 \mathrm{mg}$ RCSSS in the form of a membrane was higher than the viability of human dental pulp cells (\%) in the other treatment groups. In addition, the viability of human dental pulp cells (\%) in the treatment group that has been exposed to $1 \mathrm{mg}$ RGD chitosan from [5] shrimp shell scaffold in the form of a membrane was lower than the treatment group that has been exposed to $1 \mathrm{mg}$ CSSS in the form of a membrane, whereas the viability of human dental pulp cells (\%) in the treatment group that has been exposed to $2 \mathrm{mg}$ RCSSS in the form of a membrane was higher than the treatment group that has been exposed to $2 \mathrm{mg}$ CSSS in the form of a membrane. Based on the one-way ANOVA test with post hoc (Tukey-Bonferonni), there was a significant difference between the viability of human dental pulp cells (\%) in the treatment group exposed to $1 \mathrm{mg}$ RCSSS in the form of a membrane and the treatment group exposed to $1 \mathrm{mg}$ CSSS in the form of a membrane $(\mathrm{p}<0.05)$. Furthermore, there was also a significant difference between the viability of human dental pulp cells (\%) in the treatment group exposed to $2 \mathrm{mg}$ RCSSS in the form of a membrane and the treatment group exposed to $2 \mathrm{mg}$ CSSS in the form of a membrane $(\mathrm{p}<0.05)$.

Furthermore, the viability of human dental pulp cells (\%) in the treatment group exposed to $2 \mathrm{mg}$ RCSSS in the form of a membrane was higher than the treatment group exposed to $1 \mathrm{mg}$ CSSS in the form of a membrane. Based on the one-way ANOVA test with post hoc (Tukey-Bonferonni), there was a significant difference between the

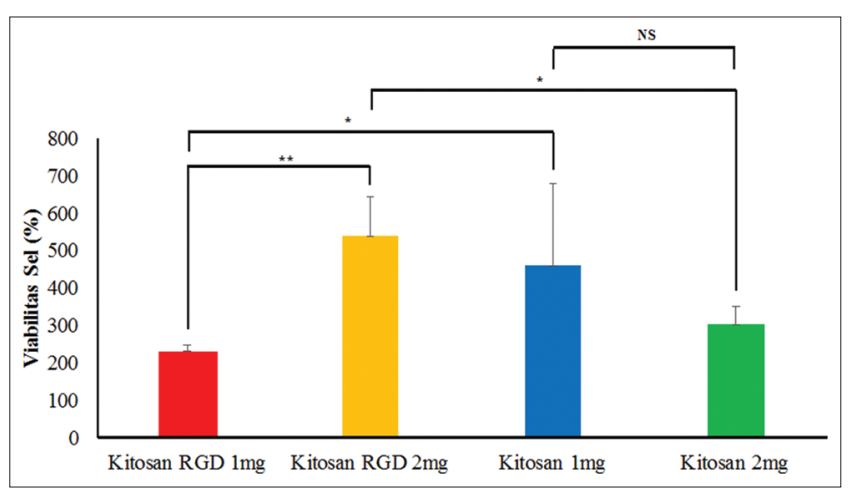

Fig. 4: Comparison of the treatment group viability of human dental pulp cells (\%) in the treatment group exposed to $2 \mathrm{mg}$ RCSSS in the form of a membrane and the treatment group exposed to $1 \mathrm{mg}$ RCSSS in the form of a membrane ( $p<0.01)$. However, the result showed that there was no significant difference between the viability of human dental pulp cells (\%) in the treatment group exposed to $1 \mathrm{mg}$ CSSS in the form of a membrane and the treatment group exposed to $2 \mathrm{mg}$ CSSS in the form of a membrane.

\section{DISCUSSION}

Chitosan is a polymer that has been widely studied as a scaffold in bone tissue engineering because it has good biocompatibility and biodegradability properties and the capability to support cell proliferation. One of the most recent developments in chitosan scaffolds is to form chitosan as a membrane-shaped scaffold. Chitosan scaffolds in the shape of a membrane are expected to be able to act as a temporary bone that can adhere to and cover an anatomical area with a large defect, supporting localized cell proliferation and differentiation $[16,17]$. The cell proliferation and differentiation were primarily can be controlled by improving cell adhesion to scaffold $[6,18]$. One way to improve the cell adhesion with a chitosan scaffold is to combine the scaffold with Arg-Gly-Asp (RGD). According to the previous studies, adding RGD to a chitosan scaffold supported scaffold adhesion to tissue [11].

Currently, BATAN has been developing CSSS in the form of membranes and has combined these scaffolds with RGD. However, before these scaffolds can be used in tissue engineering, they need to be tested for biocompatibility. According to the ISO standard 10993, a biocompatibility test needs to be conducted to evaluate cell and tissue response to the biomaterial being tested [15]. In this study, a toxicity analysis of RCSSS in the form of a membrane manufactured by BATAN was performed to evaluate its toxic response when put in contact human dental pulp cells. The toxicity analysis in this study refers to the viability of human dental pulp cells (\%) after being exposed to the test material, which was the RCSSS in the form of a membrane. In this study, human dental pulp cells were used because dental pulp contains a considerable number of stem cells, and its isolation process is fairly easy to perform [19]. Moreover, according to the previous studies, stem cells from dental pulp are considered to be the right candidate for bone regeneration because of their ability to proliferate and differentiate into osteoblasts in culture [10].

The human dental pulp cells used in this study were cultured in a $\alpha$-MEM culture medium containing penicillin, streptomycin, amphotericin B, and FBS for 5 days. A cell culture had to be done in advance because to perform a toxicity analysis, the cells must in monolayer form, or reached a subconfluent state in the bottom of the well. In addition, on the $5^{\text {th }}$ day, all cells in culture had reached the log phase. The test of the cell's viability at the log-phase stage was performed to determine whether, after exposure to test material, the cells could continue proliferating or stopped, which would be characterized by a decrease in cell viability.

Based on the toxicity analysis conducted with the MTT assay method, the viability of human dental pulp cells in all treatment groups was higher than the control group. This condition showed that exposure to the test material did not decrease the viability of human dental pulp cells. This result was consistent with the previous studies that reported chitosan from shrimp shells also manufactured by BATAN improved the OD or absorbance value of macaque DPSCs cell culture based on MTT assay method [6]. This result was also consistent with other studies that combined a chitosan scaffold with RGD. In the previous studies, adding RGD to a chitosan scaffold was reported to increase the biocompatibility and cytocompatibility of the chitosan scaffold when placed with bone marrow cells. This result was also supported by other studies that indicated that modification of RGD on the surface of nanofiber chitosan could significantly improve fibroblast adhesion to the nanofiber chitosan itself [20]. Another study reported that RGD immobilization to a chitosan scaffold showed an even better ability 
to support osteoblast growth in cultures $[11,14]$. From these studies, it can be concluded that combining a chitosan scaffold with RGD can improve cell growth, so the hypothesis states that RCSSS in the form of a membrane is not toxic to human dental pulp cells can be accepted.

In the present study, the effect of the exposure of RCSSS in the form of a membrane and CSSS in the form of a membrane, weighed $1 \mathrm{mg}$ and $2 \mathrm{mg}$, respectively, to the viability of human dental pulp cells was also analyzed. This was performed to determine whether there are differences in the effect of exposure of RCSSS in the form of a membrane and CSSS in the form of a membrane without RGD to the viability of the human dental pulp cells; this was done to determine the relation between the weight used and its effect. The effect of exposure of $1 \mathrm{mg}$ RCSSS in the form of a membrane to the viability of human dental pulp cells showed no greater and significant effect than exposure from the $1 \mathrm{mg}$ CSSS in the form of a membrane. However, increasing the weight of the RCSSS in the form of a membrane exposed to $2 \mathrm{mg}$ showed a better viability with human dental pulp cells than $2 \mathrm{mg}$ CSSS in the form of a membrane.

Furthermore, based on the analysis in this study, increasing the weight of the RCSSS in the form of a membrane from $1 \mathrm{mg}$ to $2 \mathrm{mg}$ showed an improvement in the viability of human dental pulp cells; meanwhile, increasing the weight of the CSSS in the form of a membrane without RGD from $1 \mathrm{mg}$ to $2 \mathrm{mg}$ did not show improvement in the viability of human dental pulp cells. Based on the previous studies, the difference here was probably caused by the RGD. RGD in the scaffold affects cell adhesion, which indirectly causes better cell proliferation and growth [11]. This was consistent with a previous study that used a chitosan scaffold with RGD immobilization. Based on that study, the chitosan scaffold with RGD immobilization was reported to be able to support the growth of osteoblasts better than a chitosan scaffold without RGD immobilization $[11,14]$.

Based on the study conducted by Cykitta in 2016 (unpublished), a porosity test on RCSSS in the form of a membrane and CSSS in the form of a membrane that were both manufactured by BATAN showed that the pores in the RCSSS in the form of a membrane were bigger than the CSSS in the form of a membrane. The pore size probably provided better cell penetration into the RGD chitosan so that increasing the weight of the scaffold produced an even greater effect $[4,21]$. However, based on the analysis of human dental pulp cell proliferation conducted by Mariska in 2016 (unpublished) using an MTT assay, adding RCSSS in the form of a membrane did not affect the ability of the scaffold to improve the proliferation of human dental pulp cells. The difference in these results is likely from the difference in manner and time of exposure to the scaffold.

Based on the analysis, it can be concluded that there was a different effect between the exposure of RCSSS in the form of a membrane and CSSS in the form of a membrane to the viability of human dental pulp cells; here, RCSSS in the form of a membrane showed to have a greater effect. However, whether that difference was influenced by the weight or concentration still could not be explained. In addition, this study also cannot explain the relationship between the dose and the effect that occurred after exposure to the test material because this study only used two concentrations or weights.

\section{CONCLUSION}

RCSSS in the form of a membrane is not toxic to human dental pulp cells, and its effect on the viability of human dental cells is greater than the
CSSS in the form of a membrane without RGD. This result is an initial step that can be used for more research to support the effectiveness of RCSSS in the form of a membrane manufactured by BATAN. Therefore, more tests are highly recommended.

\section{REFERENCES}

1. Ge S, Zhao N, Wang L, Yu M, Liu H, Song A, et al. Bone repair by periodontal ligament stem cell-seeded nanohydroxyapatite-chitosan scaffold. Int J Nanomed 2012;7:5405-14.

2. Arca HÇ, Şenel S. Chitosan based systems for tissue engineering part 1: Hard tissues. Fabad J Pharm Sci 2008;33(1):35-49.

3. Amini AR, Laurencin CT, Nukavarapu SP. Bone tissue engineering: Recent advances and challenges. Crit Rev Biomed Eng 2012;40(5):363-408.

4. Rodríguez-Vázquez $\mathrm{M}$, Vega-Ruiz $\mathrm{B}$, Ramos-Zúñiga $\mathrm{R}$, Saldaña-Koppel DA, Quiñones-Olvera LF. Chitosan and its potential use as a scaffold for tissue engineering in regenerative medicine. Biomed Res Int 2015;2015:821279.

5. Huang GT, Gronthos S, Shi S. Mesenchymal stem cells derived from dental tissues vs. Those from other sources: Their biology and role in regenerative medicine. J Dent Res 2009;88(9):792-806.

6. Amir LR, Suniarti DF, Utami S, Abbas B. Chitosan as a potential osteogenic factor compared with dexamethasone in cultured macaque dental pulp stromal cells. Cell Tissue Res 2014;358(2):407-15.

7. Soeroso Y, Bachtiar EW, Bachtiar BM, Sulijaya B, Prayitno SW. The prospect of chitosan on the osteogenesis of periodontal ligament stem cells. J Int Dent Med Res 2016;9(2):93-7.

8. Saravanan S, Leena RS, Selvamurugan N. Chitosan based biocomposite scaffolds for bone tissue engineering. Int $\mathrm{J}$ Biol Macromol 2016;93:1354-65.

9. Dash M, Chiellini F, Ottenbrite RM, Chiellini E. Chitosan - A versatile semi-synthetic polymer in biomedical applications. Prog Polym Sci 2011;36(8):981-1014.

10. Graziano A, d'Aquino R, Laino G, Papaccio G. Dental pulp stem cells: A promising tool for bone regeneration. Stem Cell Rev 2008;4(1):21-6.

11. Tsai WB, Chen YR, Liu HL, Lai JY. Fabrication of UV-crosslinked chitosan scaffolds with conjugation of RGD peptides for bone tissue engineering. Carbohydr Polym 2011;85(1):129-37.

12. Riahi N, Liberelle B, Henry O, De Crescenzo G. Impact of RGD amount in dextran-based hydrogels for cell delivery. Carbohydr Polym 2017;161:219-27.

13. Bellis SL. Advantages of RGD peptides for directing cell association with biomaterials. Biomaterials 2011;32(18):4205-10.

14. Tsai WB, Chen YR, Li WT, Lai JY, Liu HL. RGD-conjugated UVcrosslinked chitosan scaffolds inoculated with mesenchymal stem cells for bone tissue engineering. Carbohydr Polym 2012;89(2):379-87.

15. Wang MO, Etheridge JM, Thompson JA, Vorwald CE, Dean D, Fisher JP. Evaluation of the in vitro cytotoxicity of cross-linked biomaterials. Biomacromolecules 2013;14(5):1321-9.

16. O'Brien FJ. Biomaterials and scaffolds for tissue engineering. Mater Today 2011;14(3):88-95.

17. Zahra J. Chitosan: A brief review on structure and tissue engineering application. J Appl Tissue Eng 2014;1(1):3-7.

18. Zhu W, Liang M. Periodontal ligament stem cells: Current status, concerns, and future prospects. Stem Cells Int 2015;2015:972313.

19. Pisciotta A, Carnevale G, Meloni S, Riccio M, De Biasi S, Gibellini L, et al. Human dental pulp stem cells (hDPSCs): Isolation, enrichment and comparative differentiation of two sub-populations. BMC Dev Biol 2015; $15: 14$

20. Wang Y, Lu LX, Feng ZQ, Xiao ZD, Huang NP. Cellular compatibility of RGD-modified chitosan nanofibers with aligned or random orientation. Biomed Mater 2010;5(5):50201.

21. Enrique D, Jos P, Sobral A, Norte C. The effect of processing parameters and solid concentration on the microstructure and pore architecture of gelatin-chitosan scaffolds produced by freeze-drying. Mater Res 2016;19(4):839-45. 